\title{
Conclusion: The Task of the Social Innovation Movement*
}

\author{
Roberto Mangabeira Unger ${ }^{\dagger}$
}

\section{The social innovation movement: its defining impulse}

Social innovation is a practice that is becoming a worldwide movement. I address it in its better nature and take it at its most ambitious. In this spirit I consider in turn the circumstance, the work, the direction and the methods of the movement.

The shared impulse of all versions and understandings of social innovation is the effort to design initiatives in a particular part of society - an organisation, a practice or an area of activity - that signal a promising path of wider social change even as they meet a pressing need. The innovations that the movement seeks to advance convert experiments designed to solve social problems into transformative ambition: the effort to change some part of the established arrangements and assumptions of society. The focus of the movement falls on problems that have not been solved by either the state or the market.

The hopeful truth, from which all versions of this practice begin, is that the established ways in which society provides for its own revision never exhaust the ways in which it can be changed. This truth, in turn, rests on two facts: one about society; the other about us.

The fact about society is that our social life contains more than the market and the state. Social experience is never just the sum of our economic and political activities. Our conceptions of a market economy or of a political democracy are always wedded to flawed, relatively accidental institutional arrangements. We must occasionally resist and redesign

\footnotetext{
* This chapter is the revised transcript of a talk given on November 15, 2013 at the Social Frontiers Conference in London.

$\dagger$ (C) Roberto Mangabeira Unger
} 
these arrangements for the sake of interests and ideals that they fail to satisfy. Meanwhile, we retain an inexhaustible reservoir of vision and of contrariness. Once this power of resistance enlists practical ingenuity and living social forces in its service, it can do more than may seem feasible.

The fact about us is that we are the beings who never entirely fit into the social and conceptual worlds that we build and inhabit. There is always more in us than in them. Although we can improve them, we can never improve them enough to lose reasons to resist them. We can indeed we must - deny them the last word, and keep it for ourselves. We can - indeed we should - see, do and create more than they countenance.

Social innovation is the creation of a new way of acting and cooperating in some part of society. As society is divided into distinct domains that are arranged according to different rules and conceptions - the worlds of business, of politics, of social services, of the 'third sector', of the academy or of the media - the practice of social innovation must always begin in one of these areas. It must identify a problem that has not been solved in that corner of society and that cannot be solved by its conventional practices and established institutions. It must exemplify, through a practical initiative, a way of understanding the problem and of dealing with it.

It must do its work in such a way that the initiative does more than address the immediate problem. It must also suggest a path for the reform of the part of social life in which it began, with implications for the larger society. For example, if it begins as business it must be successful as business and yet effective as well in the advancement of a concern that business, as now organised, commonly fails to share. Its innovations must point beyond themselves.

Today the opportunity for such a practice is likely to be greatest in departments of social life that are orphaned by both the state and the market, or that lie in a netherworld between economic and political action, or that require initiatives that neither business firms nor political parties seem capable of conceiving and promoting.

Such an activity cannot take place unless it has an agent. Social regimes are organised to reproduce themselves. If they allowed no room for their own reshaping, social innovation would be impossible - except through individual and collective rebellion, in the favouring circumstance of crisis. If they had done much more to open themselves to challenge and change than they have, social innovation might be unnecessary. It is in the real, intermediate situation that social innovation becomes both needed and possible as a practice bidding to become a movement. It takes its cue from the failure of political parties and of business firms, and more generally of all established organisations in society, to do what needs to be done to address the unresolved problems of society. 
Thus arises the figure of the social innovator or social entrepreneur, the civic activist - the missing and self-created agent of the social innovation movement. He seizes on a role already established in business, politics or any other part of social life. However, in seizing on it, he uses this role incongruously. He bends and stretches it. He must be both an insider and an outsider, a practical visionary. He offers tangible down payments on another future. He envelops his tangible initiatives in a discourse promising more and anchors his promises of more in something that people can see and touch now.

It is a remarkable feature of a wide range of contemporary societies that they produce an unlimited stock of candidates for this role: men and women who are unresigned to 'the long littleness of life' and determined to place their practical powers at the disposal of a larger aspiration. These people are the lifeblood of the social innovation movement. They exist as who they are before they have a programme or know what to do. Most of them come from a faction of the professional-business class in both richer and poorer countries. Their outlook combines unwillingness to spend their lives rising through the ranks of established business and political organisations with disbelief in the dogmas that have served progressives and leftists in the past. Their public quarrel is with society. Their private quarrel is with the passage of time and the waste of life - of their own lives as well as of the lives of others.

As they struggle and search, they face two initial and connected problems. The first problem is that the empire will strike back. Their endeavours will be either suppressed or accommodated, and, if accommodated, reconciled with the established regime, unless the small changes result over time in bigger changes and the many focused actions converge and cumulate. The second problem is that they require if not a programme, at least a direction. Ingenuity is indispensable. There is, however, no substitute for vision.

\section{Minimalist and maximalist understandings of the social innovation movement}

The minimalist view of the movement is that it is headquartered in civil society and deals with civil society. According to this view, society has three large spheres: business, politics, and the residual realm of civil society, influenced and supported, but also orphaned or victimised, by both politics and business. We should think of the social innovation movement as encased within this third world sometimes called 'the third sector' - from which it emerges and to which it is addressed. 
A corollary of this minimalist conception of the setting and of the object of the movement is that it need have no comprehensive project for society. Its properly piecemeal changes are then best seen as a complement to the limitations of both business and politics.

The label 'third sector' has a reference: it refers to the world of associations and foundations, of philanthropy and do-gooding, of pro-bono activity, under secular or religious auspices, and of public and social services, insofar as they are organised from the bottom-up by society as well as provided top-down by the state. Its ideological affinity is with the traditions that are hostile to both statism and economism, to state socialism and to the established varieties of the market economy that we call capitalism. Its resonance is with solidarity and communitarianism or, more generally, with a discourse critical of classical liberalism. It nevertheless has affinities with the tradition within classical liberalism that prizes voluntary associations as well as with the strand within socialist thinking that proposes a non-statist socialism.

The minimalist view of the social innovation movement has the attraction of modesty. It is easy to mistake modesty for realism.

There is a fundamental objection to the minimalist view. Taken on its own terms, it represents both a failure of insight and a loss of opportunity.

It is a failure of insight because the truth that the powers of selfreconstruction of society are not exhausted by the present practices of the market economy and party politics fails to tell the whole story. What those practices exclude is not some potential action narrowly cabined within a third sector of life that is neither market nor state. It is rather a penumbra of accessible insight and action surrounding every aspect of present social experience. To remain blind to that penumbra, and to accept the present political and economic arrangements as the unsurpassable horizon within which the social innovation movement must act, is to reduce the movement to the job of putting a human face on an unreconstructed world. Such is already the perspective of conventional social democracy, of the fossilised forms of the confessional religions and of a secular humanism devoted to the political pieties of the day. For such work, we need no movement.

It is a loss of opportunity because there is now throughout much of the world a chance to do something more than to humanise a reality that we feel powerless to reimagine and remake: to develop institutions, practices and activities increasing our powers of agency, of individual and collective self-construction. Solidarity and community on such a basis mean something different from solidarity and community as compensations for the lack of those goods. 
There is nevertheless a legitimate point to the minimalist view that we must salvage from the illusions surrounding it. It is that although the present arrangements of business and of politics help shape all social life, they do not shape all of it equally. There are aspects of our experience, including our political and economic experience, that bear this influence more lightly. Such is the netherworld between politics and business in which we are doing something other than seeking and wielding governmental power or making and spending money. It is in this netherworld that the movement has the best chance to advance.

I here defend a maximalist view of the work to be done. According to this view, in whatever sectors the movement may take its infant steps and whatever issues it may begin by addressing, its concern should be the whole of society, of its institutional arrangements and of its dominant forms of consciousness.

Taken at its maximalist best, the social innovation movement must undertake the small initiatives that have the greatest potential to foreshadow, by persuasive example, the transformation of those arrangements and of that consciousness. It must launch such initiatives even as it seeks to redress recognised and immediate problems in a particular piece of society. Unless the horizon of transformative ambition expands to include the economic and political institutions, as well as the beliefs informing and sustaining them, the effort cannot succeed. It will be reduced to a minimalist role even if it began with maximalist aspirations. The movement had better heed the perennial maxim of those who would change the world: break or be broken.

\section{The circumstance}

We live under a dictatorship of no alternatives: only a small and inadequate set of ways of organising different fields of social life is on offer in the world. The goal of the social innovation movement, under its maximalist understanding, is to help overthrow that dictatorship.

In this situation progressives come to believe that the preservation of the essentials of the social-democratic settlement of the mid-20th century is the best for which they can hope. They retreat to what they take to be their last line of defence: the preservation of a high level of social entitlements, paradoxically funded by the regressive and indirect taxation of consumption. The problem, however, is not the retreat from that settlement so much as it is the settlement itself. The historical achievement of European social democracy - the most widely admired model of social and economic organisation in the world - was massive 
investment in people by the state. From the outset, the paramount limitation of social democracy has been that it abandoned any effort to reshape production and power: the institutional arrangements of the market and of democracy.

Today, none of the major failings of contemporary societies, richer or poorer, can be redressed within the limits of the social-democratic compromise. Its institutional conservatism and its passive acceptance of the dominant forms of consciousness condemn that compromise to near impotence. The best to which it can aspire is to soften the realities that it is unable to change or even to defy.

Among the problems that cannot be solved within the bounds of contemporary social democracy or social liberalism are all those besetting contemporary societies, including the advanced democracies of Western Europe and North America. Consider the following open list. First is the new form of the hierarchical segmentation of economies: the exclusion of the major part of the labour force from the new vanguards of production - production as permanent innovation, as experimentalism incarnate - that increasingly take the place of traditional mass production. The majority of workers are relegated to make-work. Second is the reorganisation of labour on a global scale on the basis of networks of decentralised contractual arrangements and the consequent consignment of increasing parts of the labour force to a precarious status, for which trade unionism and collective bargaining serve as inadequate antidotes. Third is the disengagement of finance from service to the real economy, accompanied by its usurpation of the lion's share of profit and talent. Rather than being a good servant, it becomes a bad master. Fourth is the ineffectiveness of using easy money and easy credit as a substitute for arrangements and policies that democratise the economy on the supply side, rather than just on the demand side. Such policies and arrangements would require an institutional redesign of the market economy, not simply its regulation by the state or the attenuation of its inequalities through retrospective, compensatory redistribution. Fifth is the failure of the present way of providing public services - the provision of low-quality, standardised services by a governmental bureaucracy to distribute the public goods that the most advanced forms of production and culture require. Sixth is the lack of any form of universal public education that would equip more than a meritocratic elite to thrive in the midst of permanent destabilisation and to reshape received knowledge. Seventh is the insufficiency of money transfers organised by the state as social entitlements to provide an adequate basis for social cohesion, especially in societies that can no longer lean on the 
crutch of ethnic and cultural homogeneity. Eighth is the continuing dependence of the flawed, low-energy democracies of the present day on crisis as the condition of change and the consequent perpetuation of the rule of the dead over the living.

What these problems have in common is that they depend for their resolution on change - piecemeal and gradual in method but nevertheless radical in ambition - in the institutional structure of society. In particular, they depend on change in the way of organising production and power. The relinquishment of any hope of changing both those arrangements and the ways of thinking with which they are associated was part of what defined the social-democratic settlement in the first place.

The reform programme embraced with either confident alacrity or sullen resignation by the governing elites of the advanced societies is no such attempt to overcome the limits of historical or chastened social democracy. It is simply the effort to make it more 'flexible' by enhancing the prerogatives of capital in the name of economic necessity.

To rebel against this circumstance and against this response is one of the starting points of the social innovation movement.

In its search for an alternative approach the movement confronts, however, a characteristic contemporary conundrum. Like the socialists and liberals of the 19th century, we contemporaries may recognise the need for structural solutions. Unlike them, however, we can no longer believe in structural dogmas: in definitive blueprints for the organisation of society. Our arrangements must, therefore, be corrigible in the light of experience; such corrigibility must become their most important attribute. Our initiatives must be informed by structural vision without succumbing to structural dogmatism.

\section{The work and its enabling conditions}

The most important resource that the activists of the social innovation movement have at their disposal is the multitude of small-scale experiments - the countless rebellions, discoveries and inventions that abound throughout the world. Their task is to identify the most promising of these experiments as points of departure for the development of more consequential alternatives: the kinds of alternatives that the servants of the dictatorship of no alternatives would rather not brook and seek preemptively to discredit.

The movement cannot perform this role without marking a direction for itself and for society. How it can reconcile the demarcation of a 
direction with the repudiation of dogmatic institutional blueprints is a conundrum that I next address.

The first criterion of choice can be readily recognised because it has the closest affinity with the practices of the movement and with the motivations of its activists: the enhancement of agency - of the ability of ordinary men and women to reshape their world. Only one word can do justice to this ideal: freedom. Those innovations must have priority that contribute most to freedom - not the theoretical freedom of the philosophers but rather freedom in practice, expressed in the ability to turn the tables on one's social and cultural setting.

The vast Brownian motion of the innovations already present in the world provides material for this pursuit. Three connected facts about society ensure that there is prospect of success.

A first enabling condition for the execution of the task of the social innovation movement is that all functional imperatives of social life such as the use of new technologies to accelerate the pace of economic growth - can always be realised through alternative institutional pathways. There is never a one-to-one relation between a functional constraint or opportunity and a way of organising the economy and the polity. Look around you and you see in the contradictions of the established social order vestiges that may also be prophecies and small breakthroughs that may be turned into larger ones.

The existing variations suggest different ways to deal with the constraints and take advantage of the opportunities. We can rarely know beforehand which will prove most beneficial. Some may be easier to implement in the short term; often, however, they will prove less fertile in the long term. Once you appreciate the range of possible response, and act on this recognition, the established regime of social life begins to lose its aura of naturalness.

A second enabling condition is that in dealing with the functional imperatives, in seizing the opportunities, in facing the constraints and in reckoning with what the economists call exogenous shocks, there always exists, in every historical circumstance, an alternative to the path of least resistance. The path of least resistance is the one minimising disturbance to the dominant interests and to the ruling preconceptions. The path of least resistance will, by definition, be the easiest one to travel. To create alternatives to the path of least resistance is the point of transformative thought and practice. It is, thus, also the concern of the social innovation movement. Those who would create such alternatives must use existing variation - the crowd of little epiphanies - as their chief resource. 
Any view of society and of its present that disregards the existence of alternatives to the path of least resistance puts mystification in the place of insight. It is retrospective rationalisation, a right-wing Hegelianism, rationalising the real, and cannot serve as a guide to action. To understand a state of affairs is to grasp what it can become under different provocations and interventions. By this criterion, it is mystification rather than insight that now prevails across the social sciences.

A third enabling condition is that there are always two main sets of ways of defining and defending group interests, including the interests of social classes or of segments of the labour force. It would do us no good for there to be alternatives in principle to the path of least resistance if real people in real groups and classes lacked grounds to identify these alternatives with their interests.

Some ways of defining and defending a group or class interest are institutionally conservative and socially exclusive. They take existing arrangements - including both the social and the technical division of labour - for granted. They cling to the niche that a given group now occupies. They see other groups, neighbouring in social and economic space, as rivals.

Other ways of defining and defending a group or class interest are institutionally transformative and socially solidaristic. They see the interest advanced through a change of arrangements that may ultimately result in its reinterpretation. They define as allies groups formerly seen as rivals. It is because group interests can be defined and defended in this way that alternatives to the path of least resistance have a fighting chance and that the social innovation movement can hope to find friends in the real forces of society.

\section{The direction}

A consequence of the maximalist understanding of the movement is that its initiatives and experiments should exemplify and foreshadow a direction for society. The movement need not and should not commit itself to a single programme for any of the societies in which the innovators act, much less to a shared worldwide programme. The innovators must nevertheless have a direction. Their direction can result only from the path that they propose for society.

Each group of participants in the movement must therefore struggle to see the social experiments that it tries to develop as the foreshadowing of such a direction. And each such direction must be defined, tentatively, by a dialectic between the innovations in practical arrangements 
and in consciousness for which it fights and the vision animating those initiatives. Music, not architecture, and sequences, not blueprints, are the handiwork of the programmatic imagination.

The two most important attributes of the ideas from which it seeks guidance are that they mark a direction and that they select, in the circumstance of action, first steps by which to begin to move in that direction. Such steps are moves in the penumbra of the 'adjacent possible' surrounding every state of affairs: the 'theres' to which we can get from here, from where we are now, with the materials at hand. These materials include existing arrangements and practices, the established stock of institutional ideas, the active social forces and the received understanding of interests and ideals, subject to the duality on which I earlier remarked.

The target of transformative ambition is always some piece of the formative institutional and ideological structure of social life: the framework of arrangements and assumptions shaping the routine contests and exchanges of a society, especially those over the control and use of the economic, political and cultural resources with which we create the future within the present. According to a prejudice resulting from the influence of necessitarian social theories, especially the theories of Karl Marx, the structures that we seek to change are indivisible systems. We must consequently choose between the revolutionary substitution of one such system by another and its reformist management. Fundamental change is wholesale; gradualism is reformist tinkering.

The truth is just the opposite: the formative institutional and ideological regimes of a society are recalcitrant to challenge and change, although we may design them to diminish this recalcitrance and to invite their own revision. However, they are not indivisible systems; they are contingent, ramshackle constructions. Change can be, and almost always is, fragmentary in scope and gradual, albeit discontinuous, in pace. Fragmentary and gradual but discontinuous change can nevertheless have radical effects if pursued, cumulatively, in a particular direction. Only because the piecemeal can be the structural can the social innovation movement do its work.

Approached in the maximalist spirit that I advocate, the social innovation movement offers a space for the experimental pursuit of a family of programmatic endeavours. The common theme - or the unifying thread - is the enhancement of agency. Such an enhancement is manifest in our power to master and to change the institutional and ideological regimes in which we move. It is expressed, as well, in the design of regimes facilitating the development and the exercise of that power. 
Within this space, different orientations may coexist, clash and converge. I outline one such orientation, describing it as a series of overlapping and reciprocally reinforcing projects in the change of both institutions and sensibilities. A vision of who we are and can become animates them. The vision acquires clarity and authority only through its expression in projects such as those that I next outline.

The first project is the advancement of what one might call 'vanguardism outside the vanguard'. In every economy, or every moment in economic history, a sector of production will be the most advanced. In that sector production most closely resembles imagination: the aspect of the mind that is neither modular nor formulaic; that enjoys the power of recursive infinity - freely to recombine everything with everything else - and that exhibits the faculty that the poet named 'negative capability', achieving insight and effect by transgressing its own methods and presuppositions.

Today the most advanced practice of production is the one that has emerged in the aftermath of mass production and its decline. It is often mistakenly equated with the high-technology industry, the terrain in which it has become best established. Its most important features go beyond the accumulation of capital, technology and knowledge. They are those that bind it to our imaginative experience: the attenuation of the contrast between conception and execution, the relativising of specialised work roles, the cultivation of common purpose and higher trust, and the development of methods of permanent innovation. When combined with their characteristic technologies, these arrangements and practices make it possible to reconcile decentralised initiative with coordination and the variation (or 'destandardisation') of products with economies of scale.

Such traits should be applicable, with suitable adjustments, to almost any sector of the economy. They should be easier to disseminate than the attributes of the productive vanguard of an earlier age: the mechanised manufacturing of the period following the Industrial Revolution. Just the opposite has happened. In the aftermath of the Industrial Revolution, every part of the economy, including agriculture, was reshaped on the model of mechanised manufacturing. The new 'postFordist' vanguards tend, on the contrary, to remain only weakly linked to other sectors of each national economy: although the technologies that they produce are widely used, the advanced practices around which they are organised remain largely foreign to major parts of even the richest economies in the world. Most of the labour force remains locked out of these vanguards. 
There are two conventional ways to counteract inequalities in the rich North Atlantic societies, as well as in the many countries that have come under the spell of their established institutions and predominant beliefs: compensatory redistribution through tax-and-transfer and the defence of small business against big business. Neither of these approaches is adequate to the task of dealing with the consequences of the new hierarchical segmentation of the economy. Any effective response must begin in innovations that result in a sustained broadening of economic and educational opportunity and that, therefore, influence the primary distribution of advantage and capability. Among such responses will be those that take the new vanguardism out of the islands to which it remains confined, and propagate its practices widely.

Today an increasing part of humanity finds itself in circumstances of precarious labour. Work is once again organised, as it was before the rise of mass production, in the form of decentralised networks of contractual arrangements: now on a worldwide basis. Countless millions of people, whether thrown into radical economic insecurity or lifted above it, aspire to a modest prosperity and independence: the petty-bourgeois perspective demonised traditionally by the Left. By default, they often fix their sights on isolated family business.

Here is a world in which the social innovation movement has a mission of immense importance: to show, by exemplary initiatives, how precarious labour and retrograde small business can be lifted up and transformed by the mastery of the new advanced practices of production. Part of the task needs to be carried out from above, in the form of arrangements associating governments with small and mediumsized firms in the advancement of vanguardism beyond the vanguard. Neither the American model of arm's-length regulation of business by government nor the Northeast Asian model of imposition of unitary trade and industrial policy by the state can do this job. We require a form of coordination between governments and firms that is decentralised, participatory and experimental. Its complement is cooperative competition - combining competition with pooling of resources among advanced small and medium-sized firms. Such innovations can serve as the points of departure for alternative regimes of private and social property - different ways of arranging the decentralised allocation of access to productive resources - that would come to coexist experimentally within the same market economy.

The cause of vanguardism outside the vanguard requires movement from the bottom up as well as well from the top down: directed to the circumstances of small business and of precarious labour and to the 
dealings of such work and such firms with local governments and communities. It is here that the social innovation movement may find some of its most rewarding endeavours.

Such initiatives in reimagining and in remaking the market economy have a horizon. They move towards an economic future in which decentralised economic activity will bear the marks of a greater freedom. Our economic arrangements will no longer radically restrict the ways in which we can cooperate across the lines of division and hierarchy in society. The market economy will cease to be fastened to a single version of itself, as alternative regimes for the access to productive resources - our systems of contract and property - come to share the same market order.

The individual worker and citizen must be and feel secure in a haven of protected immunities and capabilities - universal endowments assured by the state and unattached to particular jobs - so that the society around him can be open to perpetual innovation. Work throughout the economy, as well as in the most advanced sectors, must come to exhibit the traits of the imagination; the technical division of labour becomes then a mirror of the imaginative side of the mind.

No human being should be condemned to do the work that a machine could execute. In Adam Smith's pin factory or Henry Ford's assembly line, the worker worked as if he were a machine. We have machines, however, so that they may do for us whatever we have learned to repeat and so that our time may be saved for the not yet repeatable. Then, the combination of worker and machine will achieve its greater potential.

It is unlikely to achieve it so long as economically dependent wage labour remains the principal form of free labour. It must, as both the liberals and the socialists of the 19th century hoped, give way to the higher forms of free labour: self-employment and cooperation, combined with each other. This transition cannot take place unless we develop regimes of conditional and temporary property rights organising the coexistence of different kinds of stakeholders in the same productive resources, and thus enabling us to reconcile, to a greater extent than we now can, decentralisation and scale.

These are distant goals. In the exercise of its prophetic task, the social innovation movement must nevertheless find or invent the initiatives that might prefigure them - the first steps in the penumbra of the nearby possibles. It cannot hope to invent or find them unless it has a view of what, farther ahead, it seeks.

A second project is the reform of education and, through education, of consciousness. For the social innovation movement, the role of the 
school under democracy is to serve as the voice of the future rather than as the tool of either the state or the family. It is not enough to make the student capable of moving within the present order; it is necessary to equip him to distance himself from that order, to resist it, and to reshape it bit-by-bit and step-by-step. The school must allow him to be both an insider and an outsider, an agent who participates without surrendering.

Such an education gives pride of place to the cultivation of powers of analysis and of recombination. It prefers selective depth in the marshalling of information to encyclopaedic superficiality. It puts cooperation in teaching and learning in the place of the combination of individualism and authoritarianism. It approaches every subject dialectically, from contrasting points of view. It combines such a form of general education with practical or vocational training that accords priority to generic conceptual and practical capabilities, to the meta-capabilities suitable to an age of flexible meta-machines, rather than to job-specific and machine-specific skills. For such an education to become prevalent, especially in countries that are large, very unequal, and federal in structure, we must forge the instruments needed to reconcile local management of the schools with national standards of investment and quality.

Exemplary initiatives in education can begin at any point in this ambitious programme. They can start with the method and content, in schools providing models for the others or with the institutional setting. Or they can focus first on the requirements for reconciling local management and national standards. The innovators outside government lack the resources and powers of a state. They have, however, the advantage of their disadvantages: licence to experiment episodically, undeterred by the constraints of universal rules and vast scale.

A third project is innovation in the provision of public goods and public services beyond education. Public goods make people strong; public squalour, even when in the face of private affluence, weakens them. It inhibits the strengthening of agency that must represent the core concern of the social innovation movement.

We should not have to settle for what now exists by way of providing public services: an administrative Fordism - the provision of low-quality standardised services by a governmental bureaucracy. Nor should we need to accept the privatisation of public services in favour of profitdriven firms as the sole alternative. There is another way, with promise for the central aims of the social innovation movement.

The state should ensure universal minimums. It should also take the lead in the development of the most complicated and expensive 
services. In the broad middle range between the floor and the ceiling, government should engage civil society in the competitive and experimental provision of public services not-for-profit - for example, through cooperatives. It should finance, train, prepare and coordinate civil society outside the state to take part in the work of building people: people with an enhanced power of initiative and creation, people equipped to change both their world and themselves. It is both the most reliable means to improve the quality of public services and the most effective inducement to the self-organisation of civil society.

A fourth project is to energise and deepen democracy. A high-energy, deepened democracy meets a triple test, probing three aspects of the same advance. It increases our ability collectively to master the structure of society: its formative arrangements and assumptions. It overthrows the government of the living by the dead. It weakens the dependence of change on crisis.

Such a project requires a series of convergent institutional innovations. Some would raise the temperature of politics: the level of organised popular engagement in political life. Others would hasten the pace of politics, resolving impasse among parts of the state quickly. Others would reconcile a capacity for decisive action at the centre of government with radical, experimentalist devolution in both federal and non-federal states, so that different parts of the country or even different sectors of the economy and society can offer counter-models of the national future. Others would establish in the state a power, or even a distinct branch of government, designed and equipped to come to the rescue of groups that cannot escape exclusion or subjugation by the means of collective action available to them. And others yet would enrich representative democracy with elements of direct and participatory self-government.

The social innovation movement cannot change constitutional arrangements. It can, however, launch experiments and ideas in each of the areas covered by these needed institutional changes, experiments prefiguring the direction that it proposes. Or it can commit itself to initiatives that, by compensating for the omission or paralysis of government, evoke the missing agenda. True to character, it can show how not to wait for salvation from on high.

Both a practice and a purpose should inform and unify the pursuit of these four projects. The practice is democratic experimentalism: structural ambition cleansed of structural dogmatism and advanced through fragmentary initiatives that both mark a path and take initial 
steps in travelling it. The purpose is not simply an attenuation of inequalities. It is the enactment of experiments that show how we can move towards giving the ordinary man and woman a better opportunity to live a larger life, with greater intensity, broader scope, and stronger capabilities.

No one conception of humanity and of the self can claim uniquely to guide such an endeavour. The social innovation movement can only gain by being a field hospitable to such clashing prophecies. There they will be received, developed and tested less as abstract doctrines than as messages that we read into actions the better to find directions.

For one such conception - the one that I take as my touchstone here we are the beings who - formed in social and conceptual contexts - can nevertheless immeasurably transcend the regimes of society and of thought that we inhabit. Because there is always more in us than there is, or ever can be, in them, we can exceed them and remake them. We can reduce the extent to which they imprison us and deny or suppress our powers of defiance and reinvention.

\section{The methods}

There are two chief methods by which the social innovation movement can advance projects such as those that I have just sketched. These practices are not just means to the larger end of enhancing agency; they are also concentrated instances of that enhancement.

The first such practice is the method of foreshadowing - foreshadowing a larger life for the ordinary man and woman. The localised and small-scale initiatives that are the province of the movement can be represented as anticipations of a trajectory under the light of a vision. Innovators can represent and develop their tangible, practical experiments as down payments on the execution of a more distant promise. It is the method of the prophets, who must join visionary insight to exemplary action: action that is exemplary because it consists in deeds that point towards a form of experience in which we can increase our purchase on the traits that most make us human.

Schopenhauer wrote that a talented man is a marksman who hits a target that others cannot hit, whereas a genius is a marksman who hits a target that others cannot see. The prophet is not the one who thinks more cleverly. He is the one who sees more. What he sees is a greater life, a higher humanity, an increase of our share in some of the attributes - especially the attribute of transcendence - that we regard as divine and rightly or wrongly may attribute to God. That vision must 
be translated into exemplary deeds, giving palpable signs - signs that we can experience now - of such an existence.

The inherited image of the prophet is that of an inspired individual conveying a message that is vouchsafed to him by virtue of his special proximity to the divine. He then gathers around himself a band of followers who may reduce his teaching to writing. He and they have an ambivalent relation to the temporal authorities of the societies in which they emerge.

The core creed of democracy is faith in the constructive genius of ordinary men and women and therefore as well in the dissemination of prophetic powers among them. The democratic answer to the question 'Who is the prophet?' must be: everyone. Everyone can and should act, according to his circumstance, in a prophetic spirit. Society and culture may be so organised that they either nurture or discourage the widespread development and exercise of such powers.

The social innovation movement must be, in this sense, prophetic. It must both act in a prophetic spirit and use the instruments characteristic of prophecy under democracy. Therein lies the larger meaning of the method of foreshadowing.

The second practice distinguishing the movement is the method of incursion - innovation in our economic and political arrangements, proposed and launched from a base outside both the economy and politics. The innovators have a seat in civil society outside both the state and the market. The powers of society are never reduced to the activities of market exchange or of governmental politics alone.

It is in society, insofar as it is not wholly shaped by our economic and political arrangements, that the social innovation movement finds the cradle in which it is nurtured. The category of the 'third sector' is inadequate to describe this reality; a set of 'third-sector' or non-governmental organisations is no more than a fragment of this vast part of social experience, which towers, as if it were a horizon, over both the market and the state.

It is from some place in those trans-political and trans-economic parts of society that the social innovators most often begin their work. (Social innovators may also take their point of departure from some place within either market action or governmental activity. Then they often have to face, at the outset, obstacles that the innovators who start outside the economy and the state would have to confront only when they later began to challenge economic or political arrangements.)

Regardless of where the social innovators take their initial steps, they do not end where they began. Having started in one part of social life, 
they push the chain of analogous experiments to another part. The divisions of social life, and the distinct criteria of success that are supposed to apply to each - profits for corporations, votes for politicians fail to impress and intimidate them. They see the deeper unity and discount the finality of the divisions. They reinvent a social initiative as an economic or a political one. To this transgression of boundaries and logics within society, I give the name 'the method of incursion'.

There is no part of society that the social innovation movement cannot engage, including corporate enterprise, the media and popular culture, the provision of public services, and the activities of charitable organisations. What matters is that in engaging each of them it remain faithful to its prophetic vocation.

\section{Constraint and opportunity}

The barriers faced by the social innovation movement, pursued under its maximalist understanding, are many and formidable. Mankind remains almost everywhere bent under the yoke of the dictatorship of no alternatives. The hegemonic project in the rich North Atlantic region - the reconciliation of European-style social protection within American-style economic flexibility, undertaken as an accommodation of the mid-20th century institutional and ideological settlement to present economic realities - excludes more ambitious innovations even if advanced by fragmentary and gradualist means. Outside the North Atlantic region, the major emerging powers have little to show by way of alternatives other than state capitalism, combined with pieces of neoliberalism and compensatory social democracy. Their potential for spiritual rebellion and institutional invention continues to be suppressed under the burdens of a mental colonialism that their increasing power makes all the more surprising.

The most insidious opposition, however, comes from the high academic culture, in which the social innovators might have expected to find friends. There, across the whole range of social and historical studies, tendencies of thought prevail that would, if they were to be believed, deny authority to what the innovators seek to accomplish.

In the hard, positive social sciences - beginning with the most influential, economics - rationalisation predominates: a way of explaining present arrangements that justifies their superiority or inevitability by suggesting that they are the outcome of a cumulative convergence to best practice. In the normative disciplines of political philosophy and legal theory, humanisation takes over: an appeal to pseudo-philosophical justifications of the 
ameliorative practices of compensatory and retrospective redistribution and of the systematic idealisation of law in the vocabulary of impersonal policy and principle. In the humanities, consciousness embarks on an adventurism of subjectivity detached from any disposition to reimagine and to remake the present regime of society.

The representatives of these three tendencies are practical allies in the disarmament of the transformative imagination and of the transformative will. The convergent and cumulative effect of their ways of thinking is to cut the connection - on which all insight depends - between the understanding of the present settlement and the imagination of its accessible transformations. The consequence for the social innovation movement is that it must develop its own social theory along the way, raiding the counter currents within the academy for whatever help they can provide.

No matter. The opportunity is enormous. The message has been carried throughout the world that ordinary men and women are not as ordinary as they appear to be and that every human being has a vocation for a higher life and contains infinities within him- or herself. Contemporary societies cannot solve, or even address, their fundamental problems within the restraints of the very limited stock of institutional options for the organisation of different parts of society that are now available. Meanwhile, most people remain condemned to live small and demeaning lives, even when they have escaped the extremes of poverty and oppression.

Humanity, however, seethes, churns and searches, everywhere generating a multitude of small-scale experiments from which larger changes might begin. The world chafes, restless, under the dictatorship of no alternatives. Let this restless world find an unexpected ally in the social innovation movement.

Except where otherwise noted, this work is licensed under a Creative Commons Attribution 3.0 Unported License. To view a copy of this license, visit http://creativecommons.org/licenses/by/3.0/ 